\title{
TRATAMENTO DA HIPERCALCEMIA E HIPOCALCEMIA
}

\author{
MANAGEMENT OF HYPERCALCEMIA AND HYPOCALCEMIA
}

Francisco J. A. Paula \& Milton C. Foss

Docentes. Divisão de Endocrinologia e Metabologia.Departamento de Clínica Médica. Faculdade de Medicina de Ribeirão Preto-USP. CorRespondêncIA: Francisco J. A Paula. Departamento de Clínica Médica. Faculdade de Medicina de Ribeirão Preto - USP. Av. Bandeirantes, 3900. CEP 14.049-900 Ribeirão Preto-SP, Brasil. Fax: (16) 6336695 email: fjpaula@fmrp.usp.br

PAULA FJA \& FOSS MC Tratamento da hipercalcemia e hipocalcemia. Medicina, Ribeirão Preto, 36: 370-374, abr./dez. 2003.

RESUMO - No ser humano normal, os níveis de cálcio sérico são mantidos dentro de uma estreita faixa de variação, independentemente do estado alimentar e da atividade física. Desta forma, é possível manter adequadamente as funções intra e extra-celular deste cátion divalente, que incluem: a) estabilidade de membrana, b) participação na cascata de coagulação, c) manutenção do produto iônico, mineral, requerido para o processo de mineralização, d) participação nos processos de excitabilidade e contração do músculo cardíaco e esquelético, e) secreção hormonal, f) segundo mensageiro, mediando a mensagem produzida pela interação de diversos hormônios com seus receptores. O controle dos níveis séricos de cálcio é realizado, principalmente, pelo PTH e 1,25 $(\mathrm{OH})_{2}$ D, que atuam em seus orgãos-alvo, o rim, o tecido ósseo e o trato gastrintestinal. Felizmente, a hipocalcemia e a hipercalcemia graves são ocorrências incomuns, mas, quando presentes, associam-se a elevado índice de morbimortalidade. No entanto, seu pronto reconhecimento e adequado tratamento reduz significativamente os riscos envolvidos e são determinantes para que ocorra uma boa evolução do quadro. Abaixo, descrevemos, de forma objetiva, a avaliação e o tratamento da hipercalcemia e hipocalcemia em sala de urgência.

UNITERMOS - Hipercalcemia. Hipocalcemia.

\section{1- HIPERCALCEMIA}

Adota-se, atualmente, que a elevação de cálcio até $12 \mathrm{mg} / \mathrm{dl}$ corresponde a uma alteração leve, cuja avaliação deve ser feita em ambulatório. Níveis de cálcio plasmático entre $12-14 \mathrm{mg} / \mathrm{dl}$ configura uma elevação moderada de cálcio, que não está associada a manifestações clínicas de hipercalcemia grave, não configura urgência médica. Enquanto isto, níveis plasmáticos de cálcio acima de $14 \mathrm{mg} / \mathrm{dl}$ correspondem a hipercalcemia grave, que se associa a um quadro amplo de manifestações clínicas, algumas das quais, como poliúria e vômitos tendem a manter ou, pior, aumentar a concentração de cálcio circulante, levando o paciente a uma piora progressiva de seu estado geral. Tal situação configura, em geral, uma urgência médica e o seu pronto reconhecimento e tratamento implicam em redução acentuada de morbimortalidade.

\section{1- Etiologia das hipercalcemias}

A manutenção da estabilidade do nível sérico cálcio é feita por uma engenhosa combinação de fatores que, em condições de equilíbrio, permite que a quantidade de cálcio, que é absorvida da dieta, seja semelhante à que é excretada por via urinária. Assim, a reserva óssea de cálcio é mantida estável. A hipercalcemia surge, quando os componentes mobilizadores de calcio são mais ativos que os de utilização. Diver- 
sas substâncias podem estar envolvidas com o surgimento de hipercalcemia p.ex. PTH, o PTHRP (Proteína relacionada ao $\mathrm{PTH}), 1,25(\mathrm{OH})_{2} \mathrm{D}_{3}$ e diversas citocinas (interleucina $1 \alpha$, interleucina 6 , TNF, linfotoxina) $)^{(1)}$.

A Tabela I mostra as causas de hipercalcemia. No entanto, vale a pena ressaltar que o hiperparatireoidismo primário e as doenças malignas são responsáveis por $90 \%$ dos casos de hipercalcemia. O hiperparatireoidismo primário ocorre, principalmente, em pacientes ambulatoriais, enquanto as doenças malignas são as principais responsáveis por hipercalcemia, em pacientes hospitalizados. Entre os pacientes com hipercalcemia e doença maligna, $80 \%$ apresentam tumores malignos epiteliais, os quais produzem PTHRP e, nesses casos, o envolvimento de metástase óssea é infreqüente ${ }^{(2)}$.

\section{2- Quadro clínico}

O quadro clínico do paciente hipercalcêmico é secundário à etiologia e à intensidade da hipercalcemia. Em geral, a necessidade de tratamento em urgência ocorre, quando o nível de cálcio está acima de $14 \mathrm{mg} / \mathrm{dl}$.

As repercussões gastrintestinais mais freqüentes são dispepsia, constipação, anorexia, náusea, e vômito, sendo rara a ocorrência de pancreatite. Os sintomas urinários são poliúria, polidipsia e pode ocorrer nefrocalcinose, particularmente no hiperparatireoidismo primário As manifestações neurológicas podem variar de dificuldade para concentração, sonolência e evoluir para confusão mental e finalmente coma. As manifestações cardiovasculares mais freqüentes são a hipertensão arterial e alterações de ritmo cardíaco, não sendo raro bradicardia e bloqueio do nodo AV de primeiro grau. A repercussão eletrocardiográfica mais freqüente é o encurtamento do intervalo QT. Os pacientes em uso de digital são particularmente sensíveis à arritmia, uma vez que o potencial arritmogênico desta droga aumenta na presença de hipercalcemia ${ }^{(2)}$.

\section{3- Exames laboratoriais}

A avaliação laboratorial do paciente com hipercalcemia grave em urgência deve incluir: cálcio iônico fósforo, creatinina, sódio, potássio, hemograma, gasometria, amilase e eletrocardiograma. Uma amostra de PTH deve ser colhida antes do início do tratamento e será de grande valia para o diagnóstico diferencial do paciente.
Tabela 1- Causas de Hipercalcemia

Níveis de PTHi Elevados

Hiperparatireoidismo primário

Uso de lítio

Hipercalcemia familiar hipocalciúrica

Níveis de PTHi Supressos

Doenças Malignas

Produtoras de PTHRP (tumores epiteliais de pulmão, esôfago, cabeça e pescoço, ovário e bexiga).

Produtoras de 1,25( $\mathrm{OH}) 2 \mathrm{D} 3$ (linfomas)

Metástase óssea (mieloma, carcinoma de mama)

Doenças Granulomatosas (sarcoidose, tuberculose, paracoccioidomicose e lepra)

Endocrinopatias (hipertiroidismo, insufuciência adrenal)

Medicamentos (tiazídicos, vitaminas A e D, intoxicação por alumínio na IRC

Outras causas

Síndrome do leite e alcalino

Nutrição parenteral total

\section{4- Tratamento}

Como em outras situações clínicas, o tratamento de hipercalcemia é direcionado principalmente para os pacientes sintomáticos, mas, neste caso, o nível plasmático de cálcio é um importante balizador da necessidade de ministração de tratamento. Pacientes com elevação discreta de cálcio, nível inferior a $12 \mathrm{mg} / \mathrm{dl}$, usualmente são assintomáticos e não se beneficiam de terapêutica de redução de calcemia. No paciente com níveis de cálcio plasmático entre $12-14$ mg/dl, o tratamento deve ser instituído, caso haja a presença de sinais e ou sintomas de hipercalcemia. Enquanto isso, níveis de cálcio acima de $14 \mathrm{mg} / \mathrm{dl}$, confirmados, indicam a necessidade de instituição imediata de tratamento.

O tratamento envolve manobras de estímulo de excreção urinária de cálcio, a qual, se faz por meio de hidratação e posterior administração de diuréticos de alça. A reposição de volume deve ser feita em $24-48 \mathrm{~h}$ com solução fisiológica a $0,9 \%$ para suprir um deficit hídrico que usualmente é de cerca de 3-4 1. A hidratação com solução fisiológica não só aumenta a filtração glomerular como, também, diminui a reabsorção 
tubular de cálcio. A queda de cálcio com tal medida é de cerca de 1-3 mg/dl e, em geral, não é suficiente para normalizar os níveis séricos de cálcio. No paciente já hidratado, a administração de doses baixas de furosemide 10-20 mg pode ser utilizada para inibir a reabsorção de sódio e cálcio na alça de Henle. Devese evitar o surgimento de hipopotassemia e desidratação, não administrando doses excessivas de diuréticos (>80-100mg/24 h). Ressalta-se que o diurético tiazídico, ao invés de aumentar a excreção de cálcio, é poupador de cálcio e não está indicado nessa situação.

A terapêutica dirigida para redução de mobilização de cálcio ósseo pode ser uma forma eficiente de controle de hipercalcemia. Atualmente, os bisfosfonatos são, entre as substâncias disponíveis, as que têm maior capacidade de inibir a atividade dos osteoclastos e que, se usadas adequadamente, trazem poucos efeitos colaterais. No entanto, são drogas que não devem ser usadas por via oral em pacientes restrito ao leito, devido à possibilidade de esofagite de refluxo. Em nosso meio, existe disponibilidade para uso EV de pamidronato, o qual deve ser administrado na dose de 60-90 mg diluídos em 250-500 ml de soro fisiológico, em um período de $4 \mathrm{~h}$. Hipertermia pode ocorrer freqüentemente após a infusão e outros efeitos colaterais, como mialgia e leucopenia transitória, são raros. Alguns pacientes podem apresentar manifestações de hipocalcemia. O efeito máximo de ação pode demorar mais que $24 \mathrm{~h}$ para se estabelecer e o tempo total de ação é variável, podendo variar de alguns dias a várias semanas.

Calcitonina pode reduzir a calcemia, por inibir a reabsorção óssea e estimular a excreção urinária de cálcio. A vantagem da calcitonina é que sua ação é mais rápida que a das outras drogas, que têm ação hipocalcemiante. No entanto, seu efeito é efêmero e o distúrbio tende a recidivar após $24 \mathrm{~h}$, apesar da continuidade do tratamento. A combinação de calcitonina com bisfosfonatos é interessante por possibilitar uma queda mais rápida e persistente da calcemia. A dose a ser utilizada é de 4-8 UI/Kg, administrada por via SC ou IM cada 6-8 h.

Os glicocorticóides têm lugar no tratamento de hipercalcemia, quando a etiologia está relacionada à elevação de $1,25(\mathrm{OH})_{2} \mathrm{D}_{3}$. Portanto, estão indicados em pacientes com linfoma, doença granulomatosa ou com intoxicação por vitamina $\mathrm{D}$. A dose preconizada é de 200 a 300mg de hidrocortisona EV durante 3-5 dias.
A diálise peritoneal ou a hemodiálise podem ser utilizadas em pacientes refratários a outras medidas ou em pacientes com insuficiência renal e com elas, a queda da calcemia ocorre rapidamente.

Outras opções disponíveis são usualmente evitadas devido à toxicidade e ou potencial risco de surgimento de complicações e são a plicamicina, nitrato de gálio e fosfato.

Todas as medidas descritas acima são paliativas e devem ser seguidas, sempre que possível, do tratamento etiológico do distúrbio. É necessário lembrar que a mobilização do paciente do leito deve ser feita imediatamente após a estabilização do quadro clínico e isto vai auxiliar na queda do fluxo de cálcio para a circulação.

\section{2- HIPOCALCEMIA}

Os hormônios calciotróficos (PTH e 1,25OH D) têm atividade hipercalcemiante e, aparentemente, o ser humano não secreta nenhuma substância que tenha importante papel hipocalcemiante. Portanto, a queda nos níveis séricos de cálcio, em geral, surge em decorrência de falência de secreção ou de ação dos hormônios calciotróficos. A Tabela II mostra as principais causas de hipocalcemia.

\section{1- Quadro clínico}

A redução dos níveis séricos de cálcio iônico aumenta a permeabilidade de membrana ao sódio e aumenta a excitabilidade de todos os tecidos excitáveis. A alteração vai ser responsável pelos principais sintomas e sinais de hipocalcemia, os quais, em grande parte, decorrem do aumento da excitabilidade neuromuscular ${ }^{(3)}$. As manifestações mais freqüentes são: parestesia periférica e perioral, cãibra, podendo ocorrer nos casos mais graves laringoespasmo, convulsão, tetania e evoluir para óbito. A evidência clínica de manifestação cardíaca pode ficar restrita a alteração em ECG, ocorrendo aumento do intervalo Q-T. Contudo, alguns pacientes podem apresentar taquicardia e, raramente, ocorre fibrilação atrial ou ventricular. No exame físico, a presença dos sinais de Chvostek e Trousseau revelam clinicamente o aumento da neuroexcitabilidade muscular. O Chvostek é positivo, quando ocorrem miofasciculações labiais, após percussão sobre o trajeto do nervo facial. O sinal de Trousseau é pesquisado, inflando-se, no braço, um manguito a uma pressão de $20 \mathrm{mmHg}$ acima da pressão sistólica do 


\section{Tabela II - Causas de Hipercalcemia \\ 1- Relacionada ao PTH (deficiência de secreção ou resistência) \\ Iatrogênica \\ Auto-imune \\ Congênita \\ Síndrome DiGeorge \\ Mutação do sensor de cálcio \\ Associada à outra doença \\ Infiltração de metais (ferro, cobre) \\ Sarcoidose \\ Amiloidose \\ Neoplasia Metastática \\ Resistência hormonal}

2 - Não Relacionadas ao PTH

Alterações de síntese de vitamina D

Falta de exposição solar

Nutricional

Distúrbios de absorção intestinal

Insuficiência hepática e renal

Raquitismo por deficiência de 1a hidroxilase

Uso de anticonvulsivantes

Resistência a $1,25(\mathrm{OH})_{2} \mathrm{D}$

Drogas

Bisfosfonatos

Calcitonina

Nitrato de gálio

Fosfato

Politranfusão (sangue contendo citrato)

Seqüestro de cálcio

Lise tumoral

Pancreatite aguda

Síndrome de fome óssea

Após cura de hiperparatireoidismo e hipertireoidismo

paciente por três minutos. Quando positivo, ocorre espasmo carpofalangeano naquele membro ${ }^{(4)}$.

\section{2- Exames laboratoriais}

Idealmente, deve-se determinar o nível de cálcio iônico. No entanto, em situações em que apenas a dosagem de cálcio total for disponível, deve-se ficar atento a que a à possibilidade de queda seja apenas na fração de cálcio ligada à albumina. Na hipoalbuminemia, o nível de cálcio total fica baixo, porém a fração biologicamente ativa permanece normal. Nessa situação, evidentemente, os sintomas de hipocalcemia não estão presentes. A correção matemática da calcemia poderá ser feita, acrescentando-se $0,8 \mathrm{mg} /$ dl no nível de cálcio para cada grama de albumina abaixo de $4 \mathrm{~g} / \mathrm{dl}^{(4)}$. O fósforo inorgânico sérico tenderá a ser alto nos casos de hipoparatiroidismo primário, porém poderá ser baixo ou normal, quando a disfunção estiver relacionada à deficiência de vitamina $\mathrm{D}$. A determinação da concentração sérica de magnésio é importante em pacientes com hipocalcemia, particularmente, nos pacientes desnutridos, alcoolatras, diabéticos e naqueles que não respondem ao tratamento usual. Em tais situações, a hipocalcemia pode ser consequiência de depleção crônica de magnésio e a sua correção definitiva dependerá da reposição de magnésio. Radiografia de crânio pode mostrar calcificações nos gânglios da base.

\section{3- Tratamento}

A abordagem terapêutica do paciente hipocalcêmico dependerá da intensidade e da velocidade de queda dos níveis de cálcio iônico. Em um paciente com hipocalcemia crônica, níveis discretamente reduzidos de cálcio (Cálcio: 7,5-8,5 mg/dl ou $\mathrm{Ca}^{+2}=0,9$ $1,05 \mathrm{mmol} / \mathrm{l})$ e pouco sintomáticos, o tratamento pode ser realizado com administração oral de 2 a $4 \mathrm{~g}$ de cálcio elementar e reajuste da dose de vitamina D. Em pacientes com sintomas e sinais evidentes de aumento de neuroexcitabilidade, indica-se administração parenteral de cálcio. Na hipocalcemia moderada, $\mathrm{Ca}^{+2}$ $(0,7-0,95 \mathrm{mmol} / \mathrm{l})$ administrar $0,5-1,0 \mathrm{mg} / \mathrm{Kg}$, por h, de cálcio elementar e associar cálcio por via oral, assim que possível. Nos casos de hipocalcemia grave (cálcio total: $<7,0 \mathrm{mg} / \mathrm{dl}$ ou $\mathrm{Ca}^{+2}<0,7 \mathrm{mmol} / \mathrm{l}$ ) administrar 10-30ml de gluconato de cálcio diluídos em $150 \mathrm{ml}$ de soro glicosado a $5 \%$ por via, endovenosa durante o intervalo de $10 \mathrm{~min}(10 \mathrm{ml}$ de gluconato de cálcio a $10 \%$ contém $93 \mathrm{mg}$ de cálcio elementar). Em algumas situações, essa dose pode ser repetida, mas, usualmente, após administração em bolo, segue-se a infusão lenta e contínua de uma dose de 0,5-1,5 mg de cálcio elementar/Kg por h. Quando a hipocalcemia persiste, inicia-se a administração por via oral de 1 a 3 $\mathrm{g}$ de cálcio elementar e de 0,5-1,0 mg/dia de $1,25(\mathrm{OH})_{2} \mathrm{D}_{3}{ }^{(4)}$. 
PAULA FJA \& FOSS MC. Management of hypercalcemia and hypocalcemia. Medicina, Ribeirão Preto, 36: 370-374, apr./dec. 2003.

ABSTRACT - In the normal human being, the serum calcium levels are kept inside of a narrow range of variation independently of the alimentary state and of physical activity. Therefore, it is possible to maintain the physiological intra and extra-cellular role of this divalent cation which include: a) the stability of membrane, b) participation in the coagulation cascade, c) maintenance of the required mineral ionic product for the mineralization process, d) participation in the excitation and contraction in all forms of skeletal and cardiac muscle, e) hormonal secretion, f) second messenger, mediating the signal induced by the interaction of diverse hormones with their receptors. The regulation of serum calcium levels is maintained by the PTH and $1,25(\mathrm{OH})_{2} \mathrm{D}$ which control calcium influx and efflux in bone, intestine and kidney. Fortunately, severe hypocalcemia/hypercalcemia are uncommon occurrences, but when are diagnosed are associated with high index of morbidity and mortality. However, its early recognition and introduction of adequate treatment reduces significantly the involved risks and are fundamental for therapeutic success. Below, we describe a practic guide for evaluation and treatment of hypercalcemia and hipocalcemia in emergency room.

UNITERMS: - Hypercalcemia. Hypocalcemia.

\section{REFERÊNCIAS BIBLIOGRAFIA}

1 - BROWN EM. Homeostatic mechanisms regulating extracellular and intracellular calcium metabolism. In: BILEZIKIAN JP; MARCUS R \& LEVINE MA, eds. The parathyroids: Basic and clinical aspects. Raven Press, New York, $p$ 15-54, 1994.

2 -SHANE E. Hypercalcemia: Pathogenesis, clinical manifestations, differential diagnosisand management. In: FAVUS MJ, ed. Primer on the metabolic bone diseases and disorders of mineral metabolism, 4th ed, Lippincott Williams \& Wilkins, Philadelphia, p 183-186, 1999.
3 - BROADUS AE. Mineral balance and homeostasis. In: FAVUS $M J$, ed. Primer on the metabolic bone diseases and disorders of mineral metabolism, 4th ed, Lippincott Williams \& Wilkins, Philadelphia, p 74-80, 1999.

4 - PAULA FJA \& FOSS MC. Hipocalcemia, hipoparatireoidismo, pseudo-hipoparatireoidismo e pseupseudo-hipoparatireoidismo. In CORONHO V; PETROIANU A, SANTANA EM \& PIMENTA LG, eds. Tratado de endocrinologia e cirurgia endócrina, Guanabara Koogan, Rio de Janeiro, p 649-659, 2001. 